\title{
A new tetraoxa-tetraaza macrobicyclic anthracenyl luminescent receptor: control of the receptor-substrate stoichiometry
}

\author{
Cinzia Di Pietro, ${ }^{a}$ Giovanni Guglielmo, ${ }^{a}$ Sebastiano Campagna, ${ }^{*, a}$ Mario Diotti, ${ }^{b}$ Amedea \\ Manfredi $^{b}$ and Silvio Quici*,b \\ ${ }^{a}$ Dipartimento di Chimica Inorganica, Chimica Analitica e Chimica Fisica, Università di Messina, \\ I-98166 Messina, Italy \\ ${ }^{b}$ Centro CNR and Dipartimento di Chimica Organica e Industriale, Università di Milano, I-20133 \\ Milano, Italy
}

The luminescent receptor 1 incorporating anthracenyl groups as luminophores and a tetraoxa-tetraaza macrobicyclic receptor as the binding subunit has been synthesized and its interactions with $\mathrm{Ca}^{\mathrm{II}}$, investigated by fluorescence measurements, are reported. The receptor-substrate 1-Ca system is an example of multistability at the molecular level, triggered by a reversible modification of the receptor ability and evidenced by luminescence.

The change of the luminescence output of a molecular receptor in the presence of a suitable substrate is an extremely useful tool for investigating receptor-substrate interactions. ${ }^{1}$ This has stimulated great interest in the design of supramolecular receptors whose luminescence properties can be modified by guest binding. ${ }^{2}$ Moreover, such systems have recently received additional interest after it was pointed out that they could indeed open the way, together with other systems in which the luminescence output can be reversibly modified by means of an external trigger, to the development of sensors and logic devices operating at the molecular level. ${ }^{3}$ A fundamental key towards this direction is the development of new species featuring multistability, that is, capable of being switched, by taking advantage of a perturbation, between two different stable states. ${ }^{3}$

Here we present a new tetraoxa-tetraaza macrobicyclic ligand, 1, bearing two anthracenyl groups covalently bonded, through a three-carbon atom chain, on two opposite nitrogen atoms (Fig. 1), and we report its complexation behaviour with $\mathrm{Ca}^{2+}$ studied by luminescence spectroscopy and the possibility of controlling the receptor-substrate stoichiometry by an external perturbation.

Compound 1 exhibits the typical anthracene luminescence in acetonitrile solution (luminescence quantum yield, $\Phi=0.03)$. The luminescence significantly increases $(\Phi=0.11)$ upon addition of $\mathrm{Ca}\left(\mathrm{ClO}_{4}\right)_{2} \cdot 4 \mathrm{H}_{2} \mathrm{O}$ salt (Fig. 2). Titration of the luminescence intensity vs. $\mathrm{Ca}^{2+}$ concentration is fitted (Fig. 2, inset) by a non-linear equation employed by Valeur

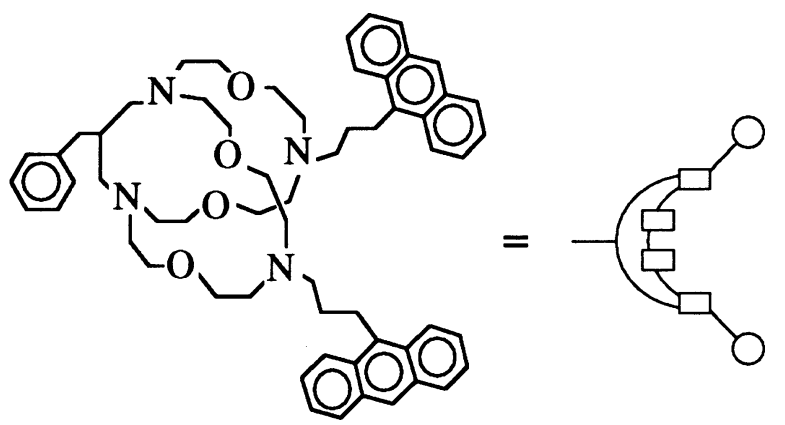

Fig. 1 Structural formula and schematic representation of 1 . In the schematic representation, the rectangles stand for the coordinating nitrogens and co-workers ${ }^{4}$ for $1: 1$ receptor-substrate adducts. The same $1: 1$ receptor-substrate adduct ratio was obtained by using the Hyperquad programme. ${ }^{5}$ The stability constants calculated by the two different methods are in fair agreement (Valeur's equation gave $4.5 \times 10^{5} \mathrm{M}^{-1}$, correlation coefficient $=0.997$; Hyperquad gave $3.0 \times 10^{5} \mathrm{M}^{-1}$, standard deviation $=0.025$ ). This behaviour agrees with a partial quenching of the anthracene luminescence in $\mathbf{1}$ due to reductive excited-state electron transfer involving the nitrogen lone pairs. $\dagger$ The experimental results as well as CPK (Corey-Pauling-Koltun) models indicate that calcium ions can be coordinated inside the tetraoxatetraaza macrobicyclic cleft of $\mathbf{1}$, giving rise to a complex 1. $\mathrm{Ca}$ with a $1: 1$ receptor- $\mathrm{Ca}^{2+}$ stoichiometry. In this complex, the nitrogen lone pairs are no longer available to quench the anthracene excited state and luminescence intensity increases. The shape of the absorption spectrum of 1 remained unchanged upon cation addition, thus indicating that there is no significant chromophore perturbation in the ground state.

Luminescence enhancement of $\mathbf{1}$ was also observed upon protonation. Titration of $\mathbf{1}$ by $\mathrm{CF}_{3} \mathrm{COOH}$, followed by changes in luminescence intensity (not shown), indicated that one equivalent of acid is enough to quantitatively protonate both of the two nitrogens connected by the 2-benzylpropylene chain of $\mathbf{1}$ (emission quantum yield of $\mathbf{1}$ in the presence of one equivalent of $\left.\mathrm{CF}_{3} \mathrm{COOH}, 0.06\right)+$ Addition of $\mathrm{Ca}^{2+}$ to an acetonitrile solution of $\mathbf{1}$ in the presence of one equivalent of acid leads to a further anthracene luminescence enhancement, but the process cannot be fitted by either Valeur's equation used for a $1: 1$ adduct or the Hyperquad programme on assuming a $1: 1$ substrate-receptor ratio. This behaviour can be explained by considering that the preferred coordination sphere of $\mathrm{Ca}^{2+}$ with crown ethers is usually made by eight donor atoms, ${ }^{8}$ while the protonated species, $\mathbf{1 H}$ has only six binding sites available for complexation. Furthermore, $\mathrm{Ca}^{2+}$ tends probably to be pushed out from the cleft by repulsive interaction with $\mathrm{H}^{+}$. Under these conditions, two molecules of

$\dagger$ Anthracene emission quenching by amine nitrogens in multicomponent systems is well-documented. ${ }^{2}$

$\ddagger$ Because of their proximity, in fact, these nitrogens cooperate to coordinate a proton. The same result was obtained in a related bis(azacrown) species of this family ${ }^{6}$ and is reminiscent of the protonation behaviour of preorganized base sites in catenands containing 1,10-phenanthroline units. ${ }^{7}$ 


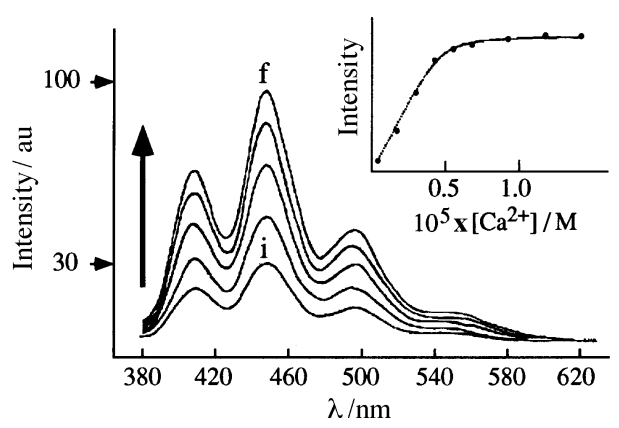

Fig. 2 Luminescence enhancement of $\mathbf{1}$ upon $\mathrm{Ca}^{2+}$ addition and (inset) fitting of the luminescence intensity vs. $\mathrm{Ca}^{2+}$ concentration by employing Valeur's equation for $1: 1$ adducts. Solvent, acetonitrile; concentration of $1,5 \times 10^{-5} \mathrm{M}$; excitation wavelength, $280 \mathrm{~nm}$; emission wavelength, $410 \mathrm{~nm}$

$1 \mathrm{H}$ are needed to complete the coordination sphere of the calcium ion. Indeed, the titration is perfectly fitted by Hyperquad when a $2: 1$ receptor-substrate ratio is assumed $\left(K_{\mathrm{a}}=\right.$ $7.9 \times 10^{10} \mathrm{M}^{-2}$, standard deviation $=0.15$ ). It should also be noted that under the conditions used in the experiments, $>90 \%$ of the luminescence enhancement is obtained when 0.5 equiv. of $\mathrm{Ca}^{2+}$ ions are added with respect to the receptor. The resulting complex can be now labelled as $\mathbf{1 H} \cdot \mathrm{Ca} \cdot \mathbf{1 H}$, with the calcium cation playing the role of an assembling chromophore species. $\$$

To explore the possibility of moving reversibly from $1 \cdot \mathrm{Ca}$ to $\mathbf{1 H} \cdot \mathrm{Ca} \cdot \mathbf{1 H}$, we alternatively added one equivalent (with respect to 1) of $\mathrm{CF}_{3} \mathrm{COOH}$ and 1,4-diazabicyclo[2.2.2] octane $(\mathrm{DABCO})$ into an acetonitrile solution containing $1\left(5 \times 10^{-5}\right.$ M) and $\mathrm{Ca}^{2+}\left(3 \times 10^{-5} \mathrm{M}\right)$. By independent experiments, it could be noted the solution containing 1 and $\mathrm{Ca}^{2+}$ in the above mentioned concentrations exhibits a luminescence intensity output (at a fixed excitation wavelength) equivalent to $70 \%$ of the luminescence intensity of the same solution in the presence of $5 \times 10^{-5} \mathrm{M}, \mathrm{CF}_{3} \mathrm{COOH}$ (Fig. 3). By taking advantage of the difference in luminescence intensity exhibited by the two adducts under such a situation, it can be seen that alternate addition of one equivalent of acid and base shifts the system from the luminescence value typical of the $1: 1$ adduct

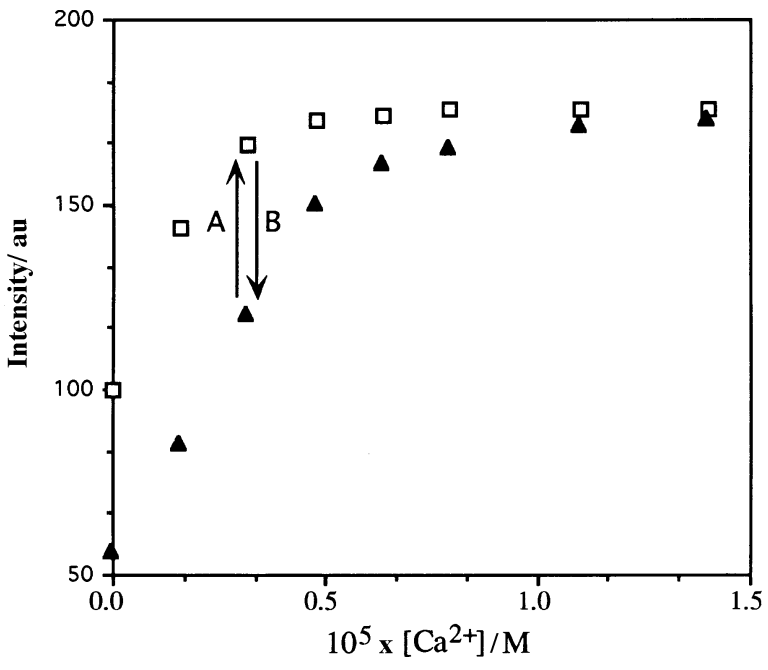

Fig. 3 Reversible shift between $\mathbf{1} \cdot \mathrm{Ca}$ and $\mathbf{1 H} \cdot \mathrm{Ca} \cdot \mathbf{1 H}$. Total concentration of 1 is $5 \times 10^{-5} \mathrm{M}$; concentration of $\mathrm{Ca}^{2+}$ is $3 \times 10^{-5} \mathrm{M}$. Square and triangles are the experimental luminescence intensities of 1 in the presence and absence of acid, respectively. A is the luminescence output change upon addition of one equivalent (with respect to 1) of $\mathrm{CF}_{3} \mathrm{COOH}$. $\mathrm{B}$ is the luminescence output change upon successive addition of one equivalent of DABCO

$\S$ The calculated value of the stability constant for $\mathbf{1 H} \cdot \mathrm{Ca} \cdot \mathbf{1 H}$ should be considered with great care, because of its extremely high value.
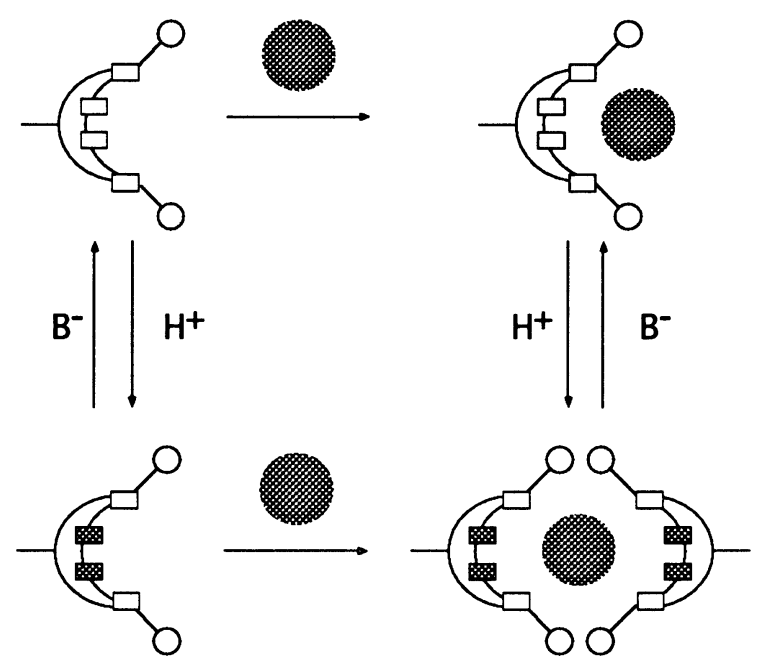

Fig. 4 Schematic representation of the reversible assembling processes. The grey rectangles represent the protonated (deactivated) nitrogens. The sphere stands for the $\mathrm{Ca}^{2+}$ ion

to that of the $2: 1$ adduct (Fig. 3), thus demonstrating that the system can be reversibly moved between two arrangements (bistability). The situation is schematized in Fig. 4.

The system reported is an example of multistability at the molecular level, triggered by a reversible modification of the receptor ability upon protonation and evidenced by luminescence. The two different states of the system are the two $(1: 1$ and $2: 1)$ receptor-substrate adducts which, under suitable concentration conditions, exhibit different luminescence intensities. 9

At the moment we are engaged in the synthesis of receptors bearing chromophores different from anthracenes (e.g., naphthalenes) to explore the possibility of driving interreceptor photoinduced energy and/or electron transfer in $2: 1$ adducts made of mixed receptors.

\section{Experimental}

The preparation of 1 was easily achieved by condensation of the corresponding tetraoxa-tetraaza macrobicyclic bisamine ${ }^{9 a}$ with 9-(3-bromopropyl)anthracene ${ }^{9 b}$ carried out in $\mathrm{CH}_{3} \mathrm{CN}$ at reflux for 6 days and solid $\mathrm{Na}_{2} \mathrm{CO}_{3}$ as base. Selected data for 1 are: ${ }^{1} \mathrm{H}$ NMR $\left(300 \mathrm{MHz}, \mathrm{CDCl}_{3}\right) \delta 1.80-2.00(\mathrm{~m}, 1 \mathrm{H}), 2.20$ $3.10(\mathrm{~m}, 34 \mathrm{H}), 3.30-3.80(\mathrm{~m}, 16 \mathrm{H}), 7.01-7.22(\mathrm{~m}, 5 \mathrm{H}), 7.30-7.53$ $(\mathrm{m}, 8 \mathrm{H}), 7.96(\mathrm{~d}, 4 \mathrm{H}, J=8.3 \mathrm{~Hz}), 8.25(\mathrm{~d}, 4 \mathrm{H}, J=8.6 \mathrm{~Hz}), 8.30$ (s, 2H). FAB-MS; found $m / z 937[\mathrm{M}+\mathrm{Na}]^{+}, 915[\mathrm{M}+1]^{+}$; calcd for $\mathrm{C}_{60} \mathrm{H}_{74} \mathrm{~N}_{4} \mathrm{O}_{4} \mathrm{Na}^{+}: m / z$ 937. Anal. calcd for $\mathrm{C}_{60} \mathrm{H}_{74} \mathrm{~N}_{4} \mathrm{O}_{4}$ : C, 78.72; H, 8.16; N, 6.12; found: $\mathrm{C}, 78.10 ; \mathrm{H}$, $8.20 ; \mathrm{N}, 6.0 \%$.

Luminescence quantum yields have been obtained with the optically dilute method, ${ }^{10}$ using anthracene in deoxygenated ethanol as standard $(\Phi=0.27) .^{11}$

Details on Valeur's equation employed to fit the data are available as supplementary material from the author.

\section{References}

1 V. Balzani and F. Scandola, Supramolecular Photochemistry, Ellis Horwood, Chichester, 1991, chap. 8.

2 (a) A. P. de Silva, H. Q. N. Gunaratne and C. P. McCoy, Nature (London), 1993, 42, 364; (b) Fluorescent Chemosensors for Ion and Molecule Recognition, ed. A. W. Czarnik, ACS Symposium Series

- The switching system represented in Fig. 4 could be considered as an example of tetrastability rather than of bistability. Such high levels of stability are very interesting because they can allow us to break out of the stranglehold of binary logic (even though binary logic has a monopoly in current computing). We thank one of the reviewers for having suggested this point. 
538, American Chemical Society, Washington, DC, 1993; (c) H. Bouas-Laurent, J.-P. Desvergne, F. Fages and P. Marsau, in Frontiers in Supramolecular Organic Chemistry and Photochemistry, eds. H.-J. Schneider and H. Dürr, VCH, Weinheim, 1991, p. 265; (d) R. Y. Tsien, Chem. Eng. News, 1994, July 18, 34; (e) L. Fabbrizzi and A. Poggi, Chem. Soc. Rev., 1995, 197; $(f)$ L. Fabbrizzi, M. Licchelli, P. Pallavicini, A. Perotti, A. Taglietti and D. Sacchi, Chem. Eur. J., 1996, 2, 75; $(g)$ A. P. de Silva, H. Q. N. Gunaratne, T. Gunnlaugsson, A. J. M. Huxley, C. P. McCoy, J. T. Rademacher and T. E. Rice, Chem. Rev., 1997, 97, 1515.

3 (a) J.-M. Lehn, Supramolecular Chemistry, VCH, Weinheim, 1995; (b) S. L. Gilat, S. H. Kawai and J.-M. Lehn, Chem. Eur. J., 1995, 1 , 275; (c) J.-P. Collin, P. Gaviña and J.-P. Sauvage, Chem. Commun., 1996, 2005; (d) A. Credi, V. Balzani, S. J. Langford and J. F. Stoddart, J. Am. Chem. Soc., 1997, 119, 2679; (e) G. M. Tsivgoulis and J.-M. Lehn, Adv. Mater., 1997, 9, 627; $(f)$ A. P. de Silva, T. Gunnlaugsson and C. P. McCoy, J. Chem. Educ., 1997, 74, 53; $(g)$ F. Pina, M. J. Melo, M. Maestri, R. Ballardini and V. Balzani, J. Am. Chem. Soc., 1997, 119, 5556.
4 J. Bourson, J. Pouget and B. Valeur, J. Phys. Chem., 1993, 97, 4552

5 A. Sabatini, A. Vacca and P. Gans, Coord. Chem. Rev., 1992, 120, 389

6 S. Quici, A. Manfredi, R. Rossi, S. Campagna, G. Calogero and V. Balzani, Gazz. Chim. Ital., 1997, 127, 107.

7 (a) N. Armaroli, L. De Cola, V. Balzani, J.-P. Sauvage, C. O. Dietrich-Bucherer, J.-M. Kern and A. Bailal, J. Chem. Soc., Dalton Trans., 1993, 3241; (b) N. Armaroli, V. Balzani, L. De Cola, C. Hemmert and J.-P. Sauvage, New J. Chem., 1994, 18, 775.

8 N. S. Poonia and A. V. Bajaj, Chem. Rev., 1979, 79, 389.

9 (a) S. Quici, A. Manfredi and M. Buttafava, J. Org. Chem., 1996, 61, 3870; (b) F. H. C. Stewart, Aust. J. Chem., 1960, 13, 478

10 J. N. Demas and G. A. Crosby, J. Phys. Chem., 1971, 75, 991

11 W. R. Dawson and M. W. Windsor, J. Phys. Chem., 1968, 72, 3251.

Received in Montpellier, France, 13th February, 1998; Revised $\mathrm{m} / \mathrm{s}$ received 12 th June 1998 ;

Letter 8/01329B 